\title{
A Preliminary Investigation on the In-Vitro Antibacterial Activities of Cave Actinomycetes
}

\author{
Asifa Mushtaq ${ }^{1 *} \cdot$ Musharaf Gul $^{2} \cdot$ Seema Rawat $^{3} \cdot$ Jay Krishan Tiwari $^{1}$ \\ ${ }^{1}$ Department of Botany and Microbiology, H.N.B. Garhwal University, Srinagar. \\ ${ }^{2}$ Department of Zoology, H.N.B. Garhwal University, Srinagar. \\ ${ }^{3}$ Microbiology Lab, School of Life Sciences, Central University of Gujarat, Gandhinagar. \\ *Corresponding author: aasifapeers@gmail.com
}

Received: 30.11.2021; Revised: 22.12.2021; Accepted: 27.12.2021

CSociety for Himalayan Action Research and Development

\begin{abstract}
Actinomycetes are prolific producers of secondary metabolites majority of which have phenomenal industrial applications. Actinomycetes recovered from cave habitats have generated a considerable interest among the scientific community with respect to their adaptability under such unique environmental conditions. Garhwal Himalaya, Uttarakhand abodes several pristine caves which have not been previously explored for the presence of actinomycetes. The present study has been undertaken to assess the in vitro antibacterial properties of actinomycetes recovered from some of the caves located in Garhwal Himalayan region. In the present study, a total of 127 actinomycetes were isolated from three distinct caves. Majority of the isolates exhibited antibacterial activity against gram-positive bacteria. Actinomycetes isolates RCM1 and SCMM1 were observed to evince promising antibacterial activities. Members of Streptomyces genus were found to be predominant in all the samples.
\end{abstract}

Keywords: Actinomycetes, caves, antibacterial, Streptomyces

\section{Introduction}

Actinomycetes are a valuable source of bioactive metabolites notably antibiotics, antitumor agents, immunosuppressive agents and enzymes, most of which are too complex to be synthesized by combinatorial chemistry (Cheng et al., 2015). The secondary metabolites produced by actinomycetes surviving in extreme habitats are presumed to be structurally different from their terrestrial counterparts due to differential expression of genes under atypical conditions and revamping mechanisms (Zhao et al., 2011). Cave ecosystems, which were rarely studied, have been attracting considerable scientific interest due to the unique environmental conditions including relatively lower but stable temperatures, limited nutrients, little energy exchange with the external environment (Gosse et al., 2019). Our understanding regarding cave microbes, especially actinomycetes diversity is confined, in spite of the fact that numerous caves have been identified and studied across the globe. The present study has been designed to get an insight of the antibacterial properties of cave actinomycetes from Garhwal Himalayan region. The study focuses on screening the actinomycetes isolated from some of the pristine caves for in vitro antagonistic activity against selected bacteria.

\section{Materials and methods}

\section{Sampling}

Different samples, viz. speleothems, soil, microbial mats, moonmilk, and wall scrapings were collected from three caves, viz. Koteshwar 
cave, Robber's cave and Sahastradhara cave located in Garhwal Himalayan region of Uttarakhand (Fig. 1) in sterile bags and

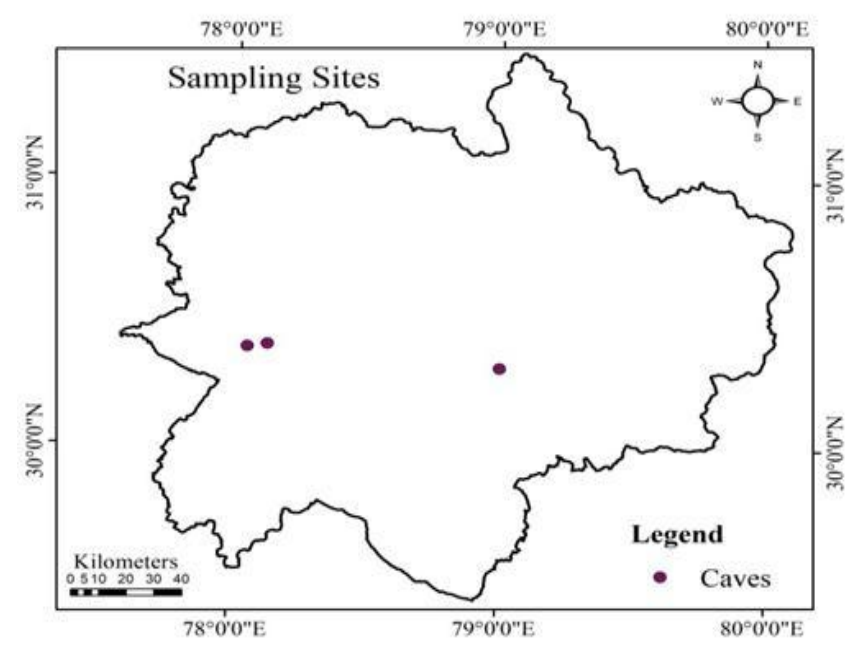

Figure 1: Geographical location of the sampling sites in Garhwal Himalaya

\section{Isolation of the culturable actinomycetes}

$1 \mathrm{gm}$ of each sample was serially diluted in $0.85 \%$ normal saline to $10^{-5}$ dilution and $0.1 \mathrm{ml}$ of diluted samples was spread on the surface of agar plates under aseptic conditions (Tiwari et al., 2015). Different selective media, viz. Actinomycete Isolation agar, Glycerol Asparagine agar, Starch Casein agar (Zainal Abidin et al., 2016) supplemented with a concentration of $25 \mu \mathrm{g} \cdot \mathrm{ml}^{-1}$ and $75 \mu \mathrm{g}$. $\mathrm{ml}^{-1}$ of cycloheximide and nalidixic acid respectively were used for the isolation of actinomycetes. All the plates were incubated aerobically at $28 \pm 2{ }^{\circ} \mathrm{C}$ for a period of 7 to 30 days and were observed regularly for appearance of the colonies. transported to the laboratory in insulated cold boxes and processed subsequently.

\section{Characterization of recovered isolates}

The isolates were identified on the basis of a combination of cultural (colony morphology, color of substrate and aerial mycelia) and microscopic features (gram-staining and slideculture techniques) typical of actinomycetes following standard protocols (Korn-Wendisch and Kutzner, 1991).

\section{Screening of recovered actinomycetes isolates for antimicrobial activity}

The recovered actinomycetes were screened for the antibacterial activity against test pathogens, viz. Enterobacter aerogenes (MTCC 6806), E. coli (MTCC 443), M. luteus (MTCC MTCC 2987), Salmonella abony (NCTC 6017), Staphylococcus aureus (MTCC 1144), Streptococcus pneumoniae (MTCC 655), and Streptococcus pyogens (MTCC 442). Primary screening of isolates for antibacterial activity against test pathogens was performed by right angle streak method (Selvameenal et al., 2009). All the isolates giving positive results in primary screening were grown in ISP2 broth medium (Kurnianto et al., 2020) in an orbital shaker at $180 \mathrm{rpm}$ for 8 to 10 days at $28 \pm 2{ }^{\circ} \mathrm{C}$. The fermented medium was centrifuged at 10,000 rpm for 10 mins to separate supernatant and the biomass. The antagonistic activity of the 
supernatant was determined against the test bacteria by agar well-diffusion method (Thumar et al., 2010).

\section{Results}

\section{Isolation and characterization of recovered isolates}

In the present work, a total of 127 actinomycetes were isolated with the help of selective isolation techniques. The colonies exhibiting growth pattern typical of actinomycetes were chosen for further analysis (Fig. 2). The colonies were aerobic, slow growing, chalky with substrate and aerial mycelia of varying colors producing an earthy odor. Some colonies were smooth while some were found to have rough consistency. Microscopy showed that the isolates were grampositive and filamentous. Most of the isolates were observed to have large and branched mycelia.
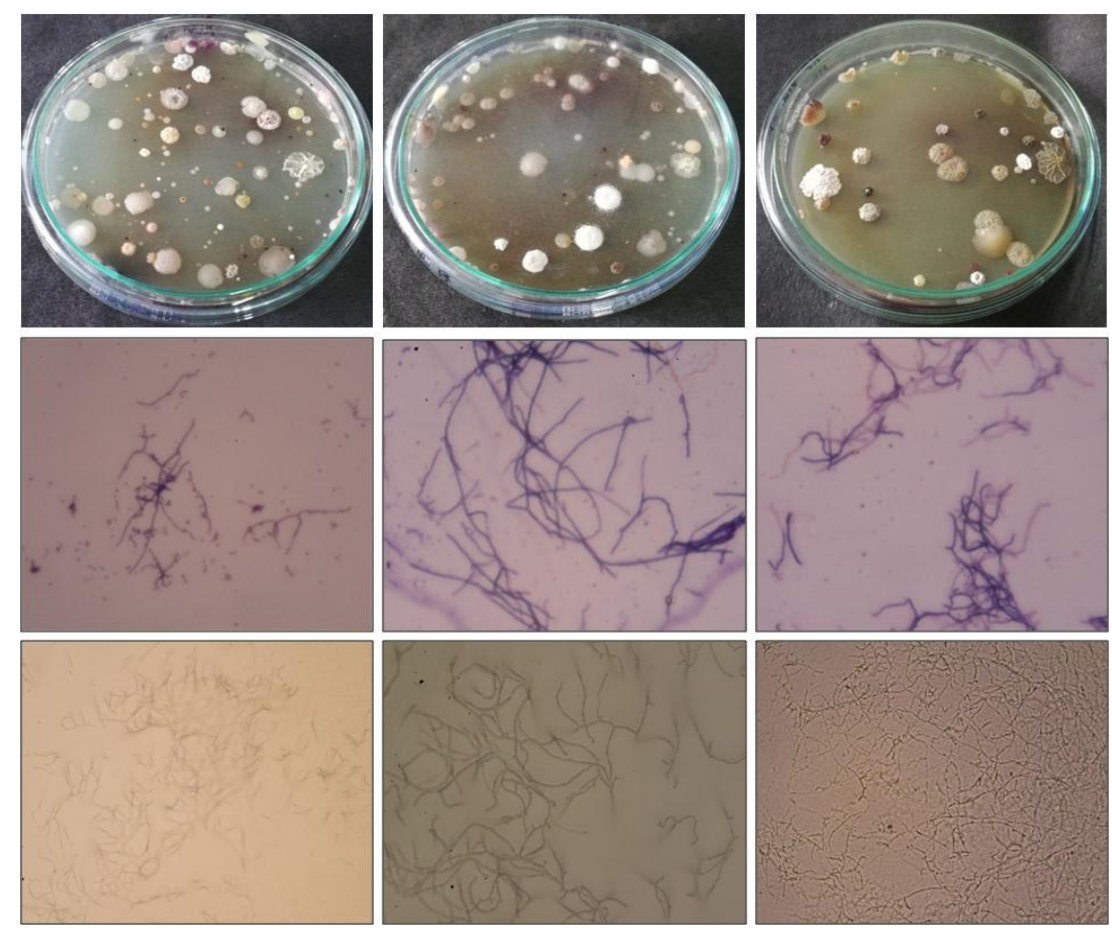

Figure 2. Representative image for the cultural and microscopic features of recovered actinomycetes isolates

\section{Screening of recovered actinomycetes isolates for antimicrobial activity}

Only $10.23 \% \quad(\mathrm{n}=13)$ of the total isolates exhibited antagonistic activity in primary screening inhibiting at least one of the test bacteria. Majority of the isolates inhibited grampositive bacteria while only $2.36 \%(n=3)$ of the total isolates exhibited antibacterial activity against gram-negative bacteria. Furthermore, it was observed that growth of M. luteus was 
inhibited by all the bioactive actinomycetes isolates while E. aerogenes and E. coli were inhibited by least number of the isolates. In the secondary screening, it was observed that out of 13 isolates, the fermented broth from only 10 isolates displayed antibacterial activity against the test bacteria (Fig. 3). The fermented broth of the isolates $\mathrm{KCM} 3, \mathrm{RC} 2, \mathrm{RCM} 30, \mathrm{SCS} 5$, SCW10, and SCW11 (46.15\% isolates) was found to exhibit poor antimicrobial activity producing zones of inhibition ranging from 3 to $11(\mathrm{~mm})$ against the test bacteria. However, the fermented broths of the isolates KCM6, SCMM1, RCM1 and RCM14 were found to exhibit significant antagonistic activity against test bacteria. The isolates RCM1 and SCMM1 were observed to inhibit all the test bacteria producing zones of inhibition ranging from 11 to $16(\mathrm{~mm})$. The highest zone of inhibition was produced by isolate RCM14 against M. luteus $18.0 \pm 1.0 \mathrm{~mm}$.

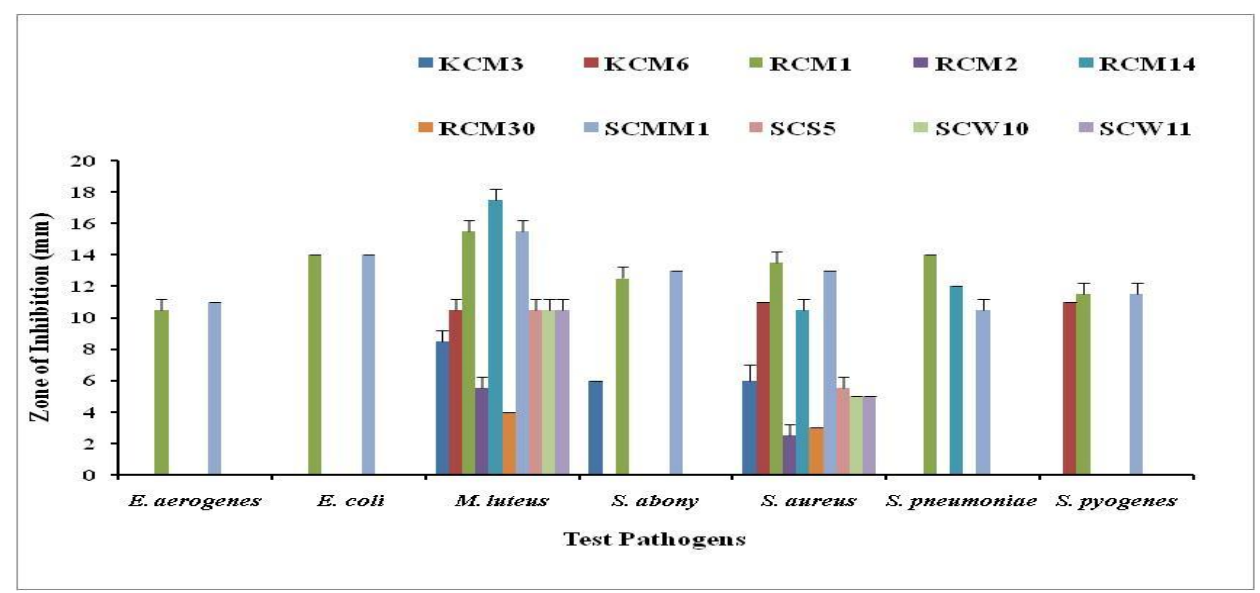

Figure 3. Zones of inhibition observed for fermented broths from representative actinomycetes isolates against test pathogens (Values expressed here are mean $\pm S D$ )

\section{Discussion}

Caves represent a diverse and largely unexplored ecosystem and the unique environmental conditions in the caves possibly favor characteristic metabolite biosynthesis in the inhabiting actinomycetes which are anticipated to be a promising source of secondary metabolites with substantial industrial applications. Our study has been designed to explore the metabolic potential of cave actinomycetes from Garhwal Himalayan region with an emphasis on the activity against wide range of bacteria.

In the present study, various samples were collected from three different caves situated at different geographical locations in Uttarakhand. A total of 127 actinomycetes isolates were recovered collectively from all the samples. Based on the morphological characterization of 
the recovered actinomycetes, majority of the isolates showed resemblances with genus Streptomyces. It was observed that the maximum number of actinomycetes isolates was recovered from soil samples which can be attributed to the higher organic matter content of cave soils. It was further observed that AIA yielded maximum number of actinomycetes from all the samples as this medium besides other selective constituents contains glycerol which promotes efficient growth of actinomycetes. Several previous studies have also emphasized the significance of selective constituents of culture media used for the isolation of actinomycetes (Rizvi et al., 2012; Dezfully and Ramanayaka, 2015). In this study, majority of the recovered actinomycetes exhibited antibacterial activity against gram-positive bacteria which can be attributed to the fundamental difference in the molecular components and the morphology of the membranes in gram-positive and gramnegative bacteria (Benhadj et al., 2019). Several other researchers have also documented the increased susceptibility of gram-positive bacteria to cave actinomycetes as compared to gram-negative bacteria (Cheeptham et al., 2013; Riquelme et al., 2017). Isolates RCM1, RCM14 and SCMM1 produced significant inhibitory zones against test bacteria emphasizing the potency of their antibacterial secondary metabolites. It was further observed in the study that most of the actinomycetes isolates exhibiting antibacterial activity displayed morphological similarities with genus Streptomyces. Our findings are in line with the previous studies highlighting the predominance of Streptomyces members recovered from diverse caves with antibacterial activity. For instance, Yücel and Yamaç (2010) have reported the potent activity of Streptomyces isolates against gram-positive bacteria $(33 \%$ of the isolates) as compared to gram-negative bacteria (27\% of the isolates) recovered from soil samples of Turkish karstic caves. This study has given us a preliminary idea on the antibacterial activities of inhabiting cave actinomycetes from Garhwal Himalayan region, simultaneously prompting us to expand our understanding on the metabolic potential of cave actinomycetes. More intensive approach with advanced experimentations needs to be undertaken to carry forward the study in order to get a clearer picture on the secondary metabolite production from cave actinomycetes.

\section{Acknowledgements}

Authors acknowledge Head, Dept. of Botany and Microbiology, H. N. B. Garhwal University Srinagar, Uttarakhand and Central University of Gujarat, Gandhinagar respectively for providing the facilities to carry out the study. One of the authors (AM) acknowledges the financial assistance provided by University Grants Commission, India as fellowship for undertaking the present work.

\section{References}


Benhadj M, Gacemi-Kirane D, Menasria T, Guebla K and Ahmane Z (2019) Screening of rare actinomycetes isolated from natural wetland ecosystem (Fetzara Lake, northeastern Algeria) for hydrolytic enzymes and antimicrobial activities. J. King Saud Uni. Sci. 31: 706-712.

Cheeptham N, Sadoway T, Rule D, Watson K, Moote P, Soliman LC, Azad N, Donkor K and Horne D (2013) Cure from the cave: volcanic cave actinomycetes and their potential in drug discovery. Int. J. Spel.42: 5.

Cheng C, MacIntyre L, Abdelmohsen UR, Horn $\mathrm{H}$, Polymenakou PN, Edrada-Ebel R and Hentschel U (2015) Biodiversity, antitrypanosomal activity screening, and metabolomic profiling of actinomycetes isolated from Mediterranean sponges. PloS one. 10: $\mathrm{e} 0138528$.

Dezfully NK and Ramanayaka JG (2015) Isolation, identification and evaluation of antimicrobial activity of Streptomyces flavogriseus, strain ACTK2 from soil sample of Kodagu, Karnataka State (India). Jundishapur J. Microbiol. 8:e15107.

Gosse JT, Ghosh S, Sproule A, Overy D, Cheeptham N, and Boddy CN (2019) Whole genome sequencing and metabolomic study of cave Streptomyces isolates ICC1 and ICC4. Front. Microbiol. 10: 1020.
Korn-Wendisch F and Kutzner HJ (1991) The family Streptomycetaceae. The Prokaryotes. A handbook on the biology of bacteria: ecophysiology, isolation, identification, applications, Springer, Berlin, Chap. 41.

Kurnianto MA, Kusumaningrum HD and Lioe HN (2020) Characterization of Streptomyces isolates associated with estuarine fish Chanos chanos and profiling of their antibacterial metabolites-crudeextract. Int. J. Microbiol. 2020: 8851947.

Riquelme C, Dapkevicius MDLE, Miller AZ, Charlop-Powers Z, Brady S, Mason C and Cheeptham N (2017) Biotechnological potential of actinobacteria from Canadian and Azorean volcanic caves. Appl. Microbiol. Biotechnol. 101: 843-857.

Rizvi R, Kamble L and Kadam A (2012) Searching the submerged: a report on prevalence of actinomycetes in sediments of river Godavari and optimized strategy for their isolation. Trends Biotechnol. Res. $1: 2$.

Selvameenal L, Radhakrishnan $\mathrm{M}$ and Balagurunathan R (2009) Antibiotic pigment from desert soil actinomycetes; biological activity, purification and chemical screening. Indian J. Pharm. Sci. 71: 499.

Thumar JT, Dhulia K and Singh SP (2010) Isolation and partial purification of an 


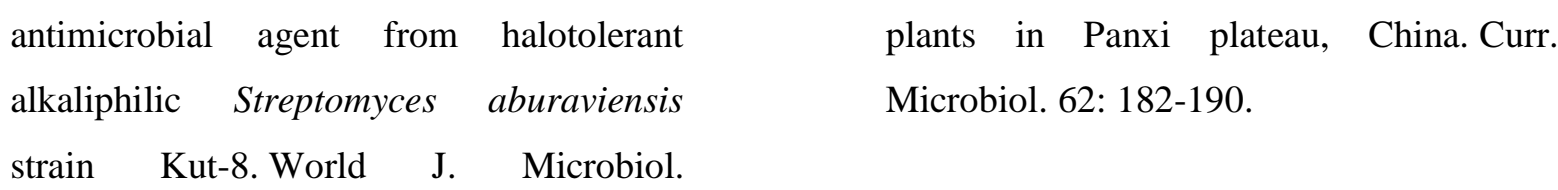

Biotechnol. 26: 2081-2087.

Tiwari K, Raj VS, Upadhyay DJ and Gupta RK (2015). In vitro activity of bioactive extracts from rare actinomycetes against multi-drug resistant Streptococcus pneumoniae. J. Appl. Microbiol. 118: 1306-1314.

Yücel S and Yamaç M (2010) Selection of Streptomyces isolates from Turkish karstic caves against antibiotic resistant microorganisms. Pak. J. Pharm. Sci. 23:1-6.

Zainal Abidin ZA, Abdul Malek N, Zainuddin Z and Chowdhury AJK (2016) Selective isolation and antagonistic activity of actinomycetes from mangrove forest of Pahang, Malaysia. Front. Life Sci. 9: 24-31.

Zhao K, Penttinen P, Guan T, Xiao J, Chen Q, Xu J, Lindström K, Zhang L, Zhang $X$ and Strobel GA (2011) The diversity and antimicrobial activity of endophytic actinomycetes isolated from medicinal 